\title{
Skeletal analysis of the long bone abnormality (lbab/lbab) mouse, a novel chondrodysplastic C-type natriuretic peptide mutant.
}

\section{$\operatorname{AUTHOR}(S):$}

Kondo, Eri; Yasoda, Akihiro; Tsuji, Takehito; Fujii, Toshihito; Miura, Masako; Kanamoto, Naotestu; Tamura, Naohisa; Arai, Hiroshi; Kunieda, Tetsuo; Nakao, Kazuwa

\section{CITATION:}

Kondo, Eri ... [et al]. Skeletal analysis of the long bone abnormality (lbab/lbab) mouse, a novel chondrodysplastic C-type natriuretic peptide mutant.. Calcified tissue international 2012, 90(4): 307-318

\section{ISSUE DATE:}

2012-04

URL:

http://hdl.handle.net/2433/155460

\section{RIGHT:}

This is a post-peer-review, pre-copyedit version of an article published in 'Calcified tissue international'. The final authenticated version is available online at: https://doi.org/10.1007/s00223-011-9567-0.; この論文は出版社版でありま せん。引用の際には出版社版をご確認ご利用ください。; This is not the published version. Please cite only the published version. 


\section{Title Page}

Eri Kondo, Akihiro Yasoda, Takehito Tsuji, Toshihito Fujii, Masako Miura, Naotestu Kanamoto, Naohisa Tamura, Hiroshi Arai, Tetsuo Kunieda and Kazuwa Nakao

Skeletal analysis of the long bone abnormality (lbab/lbab) mouse, a novel chondrodysplastic C-type natriuretic peptide (CNP) mutant

Department of Medicine and Clinical Science (E.K., A.Y., T.F., M.M., N.K., N.T., H.A., K.N.), Kyoto University Graduate School of Medicine, Kyoto 606-8507, Japan; Department of Animal Science (T.T., T.K.), Okayama University Graduate School of Natural Science and Technology, Okayama 700-8530, Japan

Corresponding author:

Akihiro Yasoda, MD, $\mathrm{PhD}$

e-mail address: yasoda@kuhp.kyoto-u.ac.jp

TEL: +81-75-751-3181

FAX: +81-75-771-9452 


\section{Abstract}

Long bone abnormality (lbab/lbab) is a strain of dwarf mice. Recent studies revealed that the phenotype is caused by a spontaneous mutation in the Nppc gene, which encodes mouse C-type natriuretic peptide (CNP). In this study, we analyzed the chondrodysplastic skeletal phenotype of lbab/lbab mice. At birth, lbab/lbab mice are only slightly shorter than their wild-type littermates. Nevertheless, lbab/lbab mice do not undergo a growth spurt, and their final body and bone lengths are only $\sim 60 \%$ of those of wild-type mice. Histological analysis revealed that the thickness of the growth plate in lbab/lbab mice, especially that of the hypertrophic chondrocyte layer, was significantly thinner than in wild-type mice. Overexpression of CNP in the cartilage of $l b a b / l b a b$ mice restored their thinned growth plate, followed by the complete rescue of their impaired endochondral bone growth. Furthermore, the bone volume in lbab/lbab mouse was severely decreased, and was recovered by CNP overexpression. On the other hand, the thickness of the growth plate of $l b a b /+$ mice was not different from that of wild-type mice; accordingly, impaired endochondral bone growth was not observed in $l b a b /+$ mice. In organ culture experiments, tibial explants from fetal lbab/lbab mice were significantly shorter than those from $l b a b /+$ mice, and were elongated by addition of $10^{-7} \mathrm{M} \mathrm{CNP}$ to the same extent as $l b a b /+$ tibiae treated with the same dose of CNP. These results demonstrate that lbab/lbab is a novel mouse model of chondrodysplasia caused by insufficient CNP action on endochondral ossification. 


\section{Key words}

C-type natriuretic peptide (CNP), long bone abnormality (lbab), chondrodysplasia, endochondral bone growth, organ culture 


\section{Introduction}

C-type natriuretic peptide (CNP) is a member of the natriuretic peptide family, and exerts its biological actions through the accumulation of intracellular cyclic GMP via a subtype of membranous guanylyl cyclase receptor, guanylyl cyclase-B (GC-B) $[1,2]$. We had previously demonstrated that the CNP/GC-B system is a potent stimulator of endochondral bone growth: transgenic mice with targeted overexpression of CNP in cartilage under the control of type II collagen promoter [3], or those with elevated plasma CNP concentrations under the control of human serum amyloid $\mathrm{P}$ component promoter [4], exhibit a prominent skeletal overgrowth phenotype. On the other hand, the physiological importance of the CNP/GC-B system on endochondral bone growth has been revealed by the phenotypes of hypomorphs. We generated complete CNP or GC-B null mice, and demonstrated that they exhibit an impaired bone growth phenotype $[5,6]$. We have also reported that two lines of spontaneous mutant mice with disproportionate dwarfism, $c n / c n$ and $s l w / s l w$, are caused by loss-of-function mutations in the murine GC-B gene [7,8]. The skeletal phenotypes of these mutant mice resemble those of GC-B knockout mice. Furthermore, recent studies have elucidated that loss-of-function mutations in the human GC-B gene are the causes of acromesomelic dysplasia type Maroteaux (AMDM), one form of skeletal dysplasias with disproportionate short stature phenotype [9]. The impaired skeletal growth phenotype observed in patients suffering from AMDM is similar to the skeletal phenotype of $c n / c n, s l w / s l w$, or GC-B knockout mice.

The long bone abnormality (lbab/lbab) mouse was first identified in The Jackson Laboratory as a spontaneous autosomal recessive mutant mouse characterized by impaired growth of long bones [10]. Recent studies have elucidated that the impaired growth of lbab/lbab mouse is caused by a hypomorphic mutation in the mouse CNP gene; Jiao et al. found that its impaired growth phenotype is associated with a single point mutation in the mouse CNP gene [11], and we showed that this phenotype is completely recovered by CNP overexpression [12]. Yoder et al. characterized the mutant CNP in lbab/lbab mouse, and exhibited that it is less biologically active than authentic CNP; in whole cell cGMP elevation and membrane guanylyl cyclase assays, 30-fold to greater than 100-fold more mutant CNP is required to activate GC-B as compared to authentic CNP [13]. We also confirmed that 
the mutant CNP in lbab/lbab mouse retains only about $10 \%$ activity to induce cyclic GMP production through GC-B compared to authentic CNP in in vitro transfection assay using COS-7 cells [12]. Collectively, lbab/lbab mouse is a novel chondrodysplastic mouse model with insufficient CNP action on endochondral bone growth. Nevertheless, the skeletal phenotypes of lbab/lbab mouse have only been partially described in short reports including our own brief communication [11-13], and have not yet been fully studied. In this study, we performed further analyses of the skeletal phenotypes of lbab/lbab mouse. 


\section{Materials and Methods}

\section{Mice}

Heterozygous (Lbab/+) mice (C57BL/6J background) were obtained from The Jackson Laboratory, and the strain was maintained by sib mating of heterozygotes. Transgenic mice with targeted overexpression of CNP in the growth plate chondrocytes under the control of the mouse pro- $\alpha_{1}$ (II) (Col2al) promoter (CNP-Tg) were created as reported previously [3]. To perform genetic rescue of $l b a b / l b a b$ mice, CNP-Tg mice were mated with $l b a b /+$ mice, and F1 offspring heterozygous for the transgene and for the Lbab allele were mated with that only for the $L b a b$ allele to generate $l b a b / l b a b$ mice with the transgene expression (lbab/lbab•CNP-Tg/+ mice) [12]. Genotypes for the CNP transgene and the Lbab allele were determined by PCR analysis using mouse genomic DNAs extracted from tails. Because there was no tendency of gender differences in the growth of each genotype (data not shown), we used only female mice in our experiments. Animal care and all experiments were conducted in accordance with the Guidelines for Animal Experiments of Kyoto University and were approved by the Animal Research Committee, Graduate School of Medicine, Kyoto University.

\section{Skeletal analysis}

For 10 weeks after birth, body lengths of female mice were measured weekly. Body length was measured as the length from the nose to the anus (naso-anal length) or that from the nose to the tip of the tail (naso-tail length). Body weights were also measured weekly. Skeletal analysis was performed as previously described [14]. Briefly, mice were subjected to soft X-ray analysis (30 kVp, $5 \mathrm{~mA}$ for 1 min, Softron type SRO-M5, Softron, Tokyo, Japan), and lengths of the bones were measured on the X-ray films. CT scanning of the humerus was performed using a ScanXmate-L090 Scanner (Comscantechno Co., Ltd., Yokohama, Japan). Three-dimensional microstructural image data were reconstructed and structural indices were calculated using TRI/3D-BON software (RATOC System Engineering Co., Ltd., Tokyo, Japan). 


\section{Histological examination}

Tibiae were fixed in 10\% formalin neutral buffer, decalcified in 10\% EDTA, and embedded in paraffin. Five-micrometer-thick sections were sliced and stained with Alcian blue ( $\mathrm{pH}$ 2.5) and hematoxylin-eosin. For immunohistochemistry, sections were incubated with rabbit anti-type $\mathrm{X}$ collagen antibody (LSL, Tokyo, Japan), goat anti-Indian hedgehog (Ihh) antibody (Santa Cruz Biotechnology, Inc., Santa Cruz, CA), mouse anti-matrix metalloproteinase 13 (MMP-13) antibody (Thermo Fisher Scientific Inc., MA), and mouse anti-proliferating cell nuclear antigen (PCNA) antibody (Dako, Copenhagen, Denmark). Immunostaining was performed using the Histofine MOUSESTAIN KIT (Nichirei Biosciences Inc., Tokyo, Japan) according to the manufacturer's instruction. Peroxidase activity was visualized using diaminobenzidine. The sections were counterstained with hematoxylin, dehydrated, and then mounted with Malinol (Muto Pure Chemicals Co., Ltd., Tokyo, Japan). To confirm antibody specificity, normal rabbit serum (Sigma-Aldrich Co., St. Louis, MO), normal goat IgG (Santa Cruz Biotechnology Inc.), and mouse IgG (Dako) were used as first antibodies for negative controls, respectively.

\section{Organ culture}

Organ culture of fetal mouse tibiae or third metatarsi was performed as described previously [15]. Tibial or metatarsal explants from $l b a b /+$ mice and their $l b a b / l b a b$ littermates at 16.5 day post coitus were cultured for 4 days with vehicle or $10^{-7}$ M CNP (Peptide Institute, Inc., Minoh, Japan). Medium was changed every day. Before and after the culture, the maximal longitudinal lengths of tibiae were measured as the total tibial length, the sum lengths of proximal and distal cartilaginous primordia (CP), and the length of osteogenic center (OC), by using a linear ocular scale mounted on an inverted microscope. For histological analysis, explants were fixed in $10 \%$ formalin neutral buffer and embedded in paraffin. Five-micrometer-thick sections were sliced and stained with Alcian blue (pH 2.5) and hematoxylin-eosin. Immunohistochemical staining of incorporated bromodeoxyuridine (BrdU) was performed using 5-Bromo-2'-deoxy-uridine Labeling and Detection Kit II (Roche Applied 
Science) according to the manufacturer's protocol.

\section{Statistical analysis}

Data were expressed as the mean \pm SEM. The statistical significance of differences between mean values was assessed using Student's $t$ test. 


\section{Results}

\section{Analyses of skeletal growth of $l b a b / l b a b$ and $l b a b /+$ mice}

As previously reported, lbab/lbab mice developed severe dwarfism characterized by short tails and extremities $[11,12]$. At birth, lbab/lbab pups were slightly shorter than their wild-type littermates: the naso-anal and the naso-tail lengths of lbab/lbab mice were $88 \%$ and $83 \%$ of those of their wild-type littermates, respectively (Fig. 1a and Supplemental Fig. 1). The ratios of naso-anal and naso-tail lengths of $l b a b / l b a b$ mice to those of wild-type mice sharply decreased to $65 \%$ and $55 \%$, respectively, by the age of 3 weeks. After 5-week-old, these ratios stabilized at to $66-72 \%$ and $57-62 \%$, respectively (Fig. 1a and Supplemental Fig. 1). The body weight of $l b a b / l b a b$ mice was $68 \%$ of that of their wild-type littermates at birth, and was decreased to $46 \%$ by the age of 3 weeks. The ratio did not increase until 5 weeks of age, but was then increased and became $\sim 60 \%$ after 7-week-old (Fig. 1b). On the other hand, the $l b a b /+$ mice were indistinguishable from their wild-type littermates at birth, and grew almost similarly as their wild-type littermates (Fig. 1a, b, and Supplemental Fig. 1). Soft X-ray analysis revealed that longitudinal growth of vertebrae, tail, and extremities was affected in $l b a b / l b a b$ mouse at the age of 2 weeks, but not affected in $l b a b /+$ mice (Fig. 1c). Histological analysis revealed that at the age of 3 days, the thickness of the tibial growth plate, especially that of the hypertrophic chondrocyte layer, of lbab/lbab mice was apparently thinner than that of wild-type mice (Fig. 1d). On the other hand, the thickness of tibial growth plate of $l b a b /+$ mice was not different from that of wild-type mice (Fig. 1d).

\section{The Effect of CNP overexpression on impaired endochondral bone growth of $l \mathrm{bab} / \mathrm{lbab}$ mice}

In order to further characterize the impaired skeletal growth of $l b a b / l b a b$ mice, we analyzed how their impaired endochondral bone growth recovered in response to targeted overexpression of CNP in the cartilage in vivo [12]. We crossed lbab/lbab mice with cartilage-specific CNP transgenic mice under the control of type II collagen promoter (CNP-Tg mice), and obtained lbab/lbab mice with transgenic expression of CNP in cartilage (lbab/lbab•CNP-Tg mice) [12]. At the first week after birth, the 
naso-anal length of $l b a b / l b a b \cdot C N P-T g$ mice was almost the same as that of $l b a b / l b a b$ mice, and considerably smaller than that of wild-type mice: naso-anal lengths of wild-type, lbab/lbab, and $l b a b / l b a b \bullet C N P-T g$ mice were $4.38 \pm 0.06,3.87 \pm 0.37$, and $4.00 \pm 0.12 \mathrm{~cm}$, respectively. Subsequently, $l b a b / l b a b \bullet C N P-T g$ mice began to grow larger than $l b a b / l b a b$ mice, and promptly caught up with wild-type mice; although the naso-anal length of $l b a b / l b a b \bullet C N P-T g$ mice was still considerably smaller than that of wild-type mice until 3 weeks of age $(5.70 \pm 0.57$ and $6.71 \pm 0.10 \mathrm{~cm}$, respectively, at the age of 3 weeks), it became almost comparable to that of wild-type mice after 4-week-old (7.38 \pm 0.48 and $7.61 \pm 0.10 \mathrm{~cm}$, respectively, at the age of 4 weeks). Further, the body weight of $l b a b / l b a b \bullet C N P-T g$ mice was almost the same as that of $l b a b / l b a b$ mice and was smaller than that of wild-type mice until the age of 3 weeks, but was then promptly increased to a level comparable to that of wild-type mice (Supplemental Fig. 2).

Soft X-ray analyses revealed that at the age of 2 weeks, the impaired growth of bones formed through endochondral ossification in lbab/lbab mice was partially recovered by targeted overexpression of CNP in cartilage in lbab/lbab•CNP-Tg mice (Fig. 2a): the recoveries in the longitudinal length of cranium and the lengths of humerus, radius, ulna, femur, tibia, and vertebra, were $35,73,68,37,51,63$, and 27\%, respectively (Fig. 2b). Furthermore, at the age of 10 weeks, the impaired endochondral bone growth in lbab/lbab mice was almost completely recovered by targeted overexpression of CNP in cartilage, as observed in lbab/lbab•CNP-Tg mice (Fig. 2c, d). On the other hand, there were no significant differences in the width of cranium, which is formed via intramembranous ossification, among the three genotypes at either 2 or 10 weeks (Fig. 2b, d).

Histological analysis showed that both the thickness of proliferative chondrocyte layer and that of hypertrophic chondrocyte layer, positive for immunohistochemical staining for type X collagen, were significantly decreased in lbab/lbab mice compared to those in wild-type mice at the age of 2 weeks, as previously reported [12] (Fig. 3a, b). The thinner proliferative chondrocyte layer in lbab/lbab growth plate was completely recovered by targeted overexpression of CNP as observed in $l b a b / l b a b \bullet C N P-T g$ growth plate (Fig. 3c). The thinner hypertrophic chondrocyte layer in $l b a b / l b a b$ growth plate was also considerably recovered in lbab/lbab•CNP-Tg growth plate, although the extent 
of the recovery was weaker than in the case of the proliferative chondrocyte layer (Fig. 3d). Immunohistochemical staining for PCNA revealed that the number of PCNA-positive cells is severely decreased in the proliferative chondrocyte layer of lbab/lbab growth plate (Fig. 3e). The number of PCNA-positive cells did not recover in the proliferative chondrocyte layer of $l b a b / l b a b \cdot C N P-T g$ growth plate, whereas the thinner proliferative chondrocyte layer in lbab/lbab growth plate was almost completely recovered in lbab/lbab•CNP-Tg growth plate (Fig. 3c). The area positive for immunostaining of Ihh, one of markers of hypertrophic differentiation, was decreased in $l b a b / l b a b$ growth plate compared to that in wild-type growth plate (Fig. 3f). The smaller size of the area positive for Ihh in $l b a b / l b a b$ growth plate was almost completely recovered in $l b a b / l b a b \bullet C N P-T g$ growth plate (Fig. 3f). Immunohistochemical staining of MMP-13, a useful marker for the terminal hypertrophic chondrocytes, was not changed between three genotypes, indicating that the progression through the hypertrophy program was not accelerated in $l b a b / l b a b$ growth plate (Fig. $3 g$ ).

At the age of 10 weeks, the tibial growth plate of $l b a b / l b a b$ mice continued to be thinner than that of wild-type mice, and was also completely recovered by overexpression of CNP in cartilage (Fig. 4).

\section{Recovery of decreased bone volume in lbab/lbab mouse by CNP overexpression}

Three-dimensional CT analysis manifested a marked reduction in bone volume of the humerus in $l b a b / l b a b$ mouse, and considerable recovery in lbab/lbab $\bullet$ CNP-Tg mouse (Fig. 5). At the age of 10 weeks, the quantified bone volume (BV/TV) and trabecular thickness (Tb. Th) of humerus in $l b a b / l b a b$ mouse were $2.4 \%$ and $34.5 \mu \mathrm{m}$, respectively, whereas those in wild-type mouse were $4.1 \%$ and $40.3 \mu \mathrm{m}$, respectively. The decreased $\mathrm{BV} / \mathrm{TV}$ and $\mathrm{Tb}$. Th in $l b a b / l b a b$ mouse were increased to $5.4 \%$ and $37.0 \mu \mathrm{m}$, respectively, in $l b a b / l b a b \bullet \mathrm{CNP}-\mathrm{Tg}$ mouse.

\section{Organ culture experiments of tibiae from lbab/lbab mice}

In order to further analyze the impaired endochondral ossification of $l b a b / l b a b$ mice, we preformed organ culture experiments using tibial explants from fetal mice (Fig. 6a) [15]. Because skeletal 
phenotypes of mice heterozygous for the $l b a b$ allele were not different from those of wild-type mice, we compared the growth of tibial explants from $l b a b / l b a b$ mice with that from $l b a b /+$ mice. At the beginning of culture, both the total length and the sum length of cartilaginous primordia (CP) of $l b a b / l b a b$ tibiae are significantly smaller than those of $l b a b /+$ tibiae $(3.80 \pm 0.04$ vs. $4.25 \pm 0.03 \mathrm{~mm}$ and $2.19 \pm 0.02$ vs. $2.43 \pm 0.01 \mathrm{~mm}$, respectively, $\mathrm{n}=8-12$, each) (Fig. 6b, c). Tibial explants from $l b a b / l b a b$ mice grew to the same extent as those from $l b a b /+$ mice during a 4-day culture period; the difference in the total length or in the length of CP between $l b a b / l b a b$ and $l b a b /+$ explants at the end of culture was comparable to that at the beginning of culture (Fig. 6b, c). There was no significant difference in the length of the osteogenic center (OC) between two genotypes before and after the culture period (data not shown).

The treatment of CNP at the dose of $10^{-7} \mathrm{M}$ stimulated the growth of both $l b a b / l b a b$ and $l b a b /+$ tibiae (Fig. 6b, c). CNP stimulated the growth of lbab/lbab tibiae more potently than that of $l b a b /+$ tibiae; in the presence of $10^{-7} \mathrm{M} \mathrm{CNP}$, the difference between the total length of $l b a b /+$ tibiae and that of $l b a b / l b a b$ tibiae was decreased (Fig. $6 \mathrm{~b}$ ), and furthermore, the CP length of $l b a b / l b a b$ tibiae became almost the same as that of $l b a b /+$ tibiae (Fig. 6c). The growth of OC was not stimulated by CNP in either $l b a b / l b a b$ or $l b a b /+$ explants (data not shown).

Histological examination at the end of culture period revealed that the length of the primordial growth plate (Fig. 7a), especially that of the hypertrophic chondrocyte layer positive for type X collagen immunostaining (Fig. $7 \mathrm{~b}, \mathrm{c}$ ), was smaller in $l b a b / l b a b$ explants than in $l b a b /+$ explants. The area positive for immunostaining for Indian hedgehog (Ihh), one of markers for chondrogenic differentiation [16], tended to be a little decreased in $l b a b / l b a b$ explants compared to that in $l b a b /+$ explants, although the intensities of the immunostaining were not changed between two genotypes (Supplemental Fig. 3). Immunohistochemical detection of BrdU-incorporated chondrocytes revealed that BrdU-positive chondrocytes tended to be decreased in lbab/lbab explants compared to those in lbab/+ explants (Fig. 7d). Addition of CNP prominently increased the lengths of primordial growth plates (Fig. 7a) and their hypertrophic chondrocyte layers (Fig. 7b, c) of both $l b a b /+$ and $l b a b / l b a b$ explants. The lengths of primordial growth plate and its hypertrophic chondrocyte layer of $l b a b / l b a b$ 
explants treated with $10^{-7} \mathrm{M} \mathrm{CNP}$ became comparable to those of $l b a b /+$ explants treated with the same dose of CNP (Fig. 7a-c). CNP increased the areas positive for Ihh immunostaining both in $l b a b /+$ and $l b a b / l b a b$ explants. By addition of CNP, the sizes of the areas positive for, and the intensities of, Ihh immunostaining became not different between in $l b a b /+$ and $l b a b / l b a b$ explants (Supplemental Fig. 3). CNP did not increased BrdU-positive chondrocytes in lbab/lbab explants (Fig. $7 d)$.

Further we explored whether CNP controls the progression of growth plate chondrocytes through the different stages of maturation or not. Because the process of endochondral ossification occurs delayed in metatarsus compared to that in tibia in an individual, we performed organ culture of metatarsi as well as tibiae from fetal mice at 16.5 day post coitus, and examined the expression of type $\mathrm{X}$ collagen and Ihh. In case of $l b a b /+$ organ culture, the area positive for immunostaining of type $\mathrm{X}$ collagen was reduced and that of Ihh was localized near the ossification center in metatarsal explants compared with those in tibial explants, indicating that metatarsal growth plate represents earlier stage of endochondral ossification than tibial growth plate (Fig. 8). The area positive for immunostaining of type X collagen was greatly reduced in lbab/lbab metatarsal explants compared with that in $l b a b /+$ metatarsal explants, and recovered by addition of $10^{-7} \mathrm{M}$ CNP to the same extent to that in $l b a b /+$ metatarsal explants treated with vehicle. The area positive for immunostaining of Ihh became closer to ossification center in lbab/lbab metatarsal explants than in $l b a b /+$ metatarsal explants, and was returned to the same position as $l b a b /+$ metatarsal explants by addition of CNP (Fig. 8). 


\section{Discussion}

Previously we and other groups had reported in brief communications that the short stature phenotype of $l b a b / l b a b$ mouse is caused by a mutation in the mouse CNP gene [11-13]. Here we further analyzed the skeletal phenotypes of $l b a b / l b a b$ mouse, and reported the results in this full-length manuscript.

Analysis of the growth curves of naso-anal and naso-tail lengths revealed that the shortness of lbab/lbab mice is mild at birth, but rapidly progresses by the age of 3 weeks, and then after 4-week-old, the ratio of the length of $l b a b / l b a b$ mice compared to that of wild-type mice becomes almost constant. This suggests that CNP is especially crucial for the skeletal growth spurt that occurs in early life. Since CNP is expressed in the growth plate cartilage and works as an autocrine/paracrine regulator [5], CNP might affect the endochondral bone growth potently when the volume of growth plate cartilage is relatively abundant.

We confirmed the thinness of the growth plate of lbab/lbab mice, especially in its hypertrophic chondrocyte layer, followed by the impaired growth of long bones. The thinness of the growth plate of $l b a b / l b a b$ mice was almost completely recovered by targeted overexpression of CNP in the growth plate by the age of 2 weeks. On the other hand, the recovery of the shortness of the total length of $l b a b / l b a b$ bones by CNP was only partial at 2-week-old, becoming complete at the age of 10 weeks. This finding suggests that the recovery is evident earlier in the thickness of the growth plate than in the total bone length. In addition, immunohistochemistry for PCNA revealed that at the age of 2 weeks, the proliferation of growth plate chondrocyte is decreased in lbab/lbab mice, and the decreased proliferation is not rescued by CNP overexpression, even though the thickness of the growth plate does fully recover. The reason why the decreased proliferation of chondrocytes in $l \mathrm{bab} / \mathrm{lbab}$ growth plate was not rescued by CNP overexpression in chondrocytes is not clear, but it may because of the weak and slow expression of the CNP-transgene owing to the weak power of the promoter region. On the other hand, CNP could not increase the proliferation of growth plate chondrocytes in lbab/lbab explants in organ culture experiment in this study. The effect of CNP on chondrocyte proliferation might be so mild that other effects of CNP on growth plate chondrocytes, e.g., the stimulatory effect on matrix synthesis as we had previously reported [3, 4], for example, might 
proceed ahead to recover the thinned growth plate of lbab/lbab mouse. The discrepancy between the effects on proliferation and matrix synthesis may explain in part the delayed recovery of bone length relative to growth plate thickness. On the other hand, immunohistochemical staining of type $X$ collagen and Thh in explanted growth plates at two different stages of endochondral ossification suggested that the progression of proliferative chondrocytes to hypertrophic chondrocytes was delayed in the $l b a b / l b a b$ growth plate and recovered by addition of CNP. In addition to the result that the expressions of MMP-13 were not different between in the terminal hypertrophic chondrocytes of wild-type, lbab/lbab, and rescued growth plates, CNP might promote the hypertrophic differentiation of proliferative chondrocytes, but not accelerate the terminal differentiation of hypertrophic chondrocytes.

In this study, we investigated the character of calcified bones of lbab/lbab mouse using three-dimensional CT analysis: the bone volume of lbab/lbab mouse was substantially decreased compared to that of wild-type mouse, and was recovered by cartilage-specific CNP overexpression. The mechanism of decrease in bone volume of lbab/lbab mouse is still unknown, but it would be postulated that CNP may be expressed in and affects on cells other than chondrocytes, i.e., osteoblasts or osteoclasts, in bone. Although overexpression of CNP was targeted to chondrocytes in our rescue experiments, early onset of the CNP-transgene expression from cartilaginous primordium might have been able to affect bone metabolism at the earlier stage of skeletogenesis [17], and may have continued to affect osteoblasts or osteoclasts near the growth plate cartilage in the later stage of skeletogenesis. Whereas several in vitro effects of CNP on osteoblastic cell lineages or osteoclasts are reported [18-28], in vivo effects of $\mathrm{CNP}$ on bone metabolism still remain elusive, and further experiments are now ongoing in our laboratory.

We previously discovered that two strains of dwarf mice, $c n / c n$ and $s l w / s l w$, are caused by spontaneous mutations in the GC-B gene [7, 8]. In humans, AMDM has been identified to be caused by spontaneous loss-of-function mutations in the GC-B gene $[9,29]$. The lbab/lbab mouse, of which skeletal phenotype we have closely analyzed in the present paper, has a spontaneous loss-of-function mutation in the mouse CNP gene; by analogy to the GC-B gene, some forms of human skeletal dysplasias might be identified to be caused by mutations in the CNP gene in future. Thus far, no such 
conditions have been discovered [30]. In the event such a discovery is made, the lbab/lbab mouse would then be a novel mouse model of a form of human skeletal dysplasias caused by a mutation in the CNP gene.

In contrast to mice homozygous for the $l b a b$ allele, the growth and skeletal phenotype of mice heterozygous for the lbab allele were not different from those of wild-type mice, as is the case with heterozygous CNP knockout mice. This confirms that haploinsufficiency for the CNP gene does not exist in mice. Likewise heterozygotes for the GC-B knockout, the $c n$ allele, or the slw allele exhibit no skeletal abnormalities [6-8]; thus, haploinsufficiency of the GC-B gene also does not exist in mice. Nevertheless, haploinsufficiency of the GC-B gene does exist in humans: heterozygous carriers of AMDM are reported to be shorter than expected for their population of origin [31]. The reason for the discrepancy is not clear at present, but may be due to differences between species or some other unknown mechanisms. We will have to perform further investigations on the skeletal phenotypes of the aforementioned lines of GC-B mutant mice; such experiments are now ongoing in our laboratory.

In summary, in this study we more closely investigated the skeletal phenotypes of a novel CNP mutant mouse, lbab/lbab. The results of this study will be useful not only for further elucidation of the physiological role of CNP on endochondral bone growth, but also for the prediction of pathophysiology of a hypothetical chondrodysplasia caused by a mutation in the human CNP gene, which has not yet been discovered. 


\section{Acknowledgments}

We thank B. de Crombrugghe (Department of Genetics, University of Texas M. D. Anderson Cancer Center) for the Col2al promoter. This work was supported by a Grant-in-Aid for Scientific Research from the Ministry of Health, Labour and Welfare of Japan and the Ministry of Education, Culture, Sports, Sciences and Technology of Japan (\# 21591176, 21119013).

\section{Disclosure of financial conflicts of interest}

The disclosure of a manuscript by authors E.K., A.Y., T.T., T.F., M.M., N.K., N.T., H.A., T.K., and K.N. may appear as follows:

DISCLOSURE STATEMENT: E.K., A.Y., T.T., T.F., M.M., N.K., N.T., H.A., T.K. and K.N. have nothing to declare. 


\section{References}

1. Nakao K, Ogawa Y, Suga S, Imura H (1992) Molecular biology and biochemistry of the natriuretic peptide system. I: Natriuretic peptides. J Hypertens 10:907-912

2. Nakao K, Ogawa Y, Suga S, Imura H (1992) Molecular biology and biochemistry of the natriuretic peptide system. II: Natriuretic peptide receptors. J Hypertens 10:1111-1114

3. Yasoda A, Komatsu Y, Chusho H, Miyazawa T, Ozasa A, Miura M, Kurihara T, Rogi T, Tanaka S, Suda M, Tamura N, Ogawa Y, Nakao K (2004) Overexpression of CNP in chondrocytes rescues achondroplasia through a MAPK-dependent pathway. Nat Med 10:80-86

4. Kake T, Kitamura H, Adachi Y, Yoshioka T, Watanabe T, Matsushita H, Fujii T, Kondo E, Tachibe T, Kawase Y, Jishage K, Yasoda A, Mukoyama M, Nakao K (2009) Chronically elevated plasma C-type natriuretic peptide level stimulates skeletal growth in transgenic mice. Am J Physiol Endocrinol Metab 297:E1339-1348

5. Chusho H, Tamura N, Ogawa Y, Yasoda A, Suda M, Miyazawa T, Nakamura K, Nakao K, Kurihara T, Komatsu Y, Itoh H, Tanaka K, Saito Y, Katsuki M, Nakao K (2001) Dwarfism and early death in mice lacking C-type natriuretic peptide. Proc Natl Acad Sci U S A 98:4016-4021

6. Tamura N, Doolittle LK, Hammer RE, Shelton JM, Richardson JA, Garbers DL (2004) Critical roles of the guanylyl cyclase B receptor in endochondral ossification and development of female reproductive organs. Proc Natl Acad Sci U S A 101:17300-17305

7. Tsuji T, Kunieda T (2005) A loss-of-function mutation in natriuretic peptide receptor 2 (Npr2) gene is responsible for disproportionate dwarfism in $\mathrm{cn} / \mathrm{cn}$ mouse. $\mathrm{J}$ Biol Chem 280:14288-14292

8. Sogawa C, Tsuji T, Shinkai Y, Katayama K, Kunieda T (2007) Short-limbed dwarfism: slw is a new allele of Npr2 causing chondrodysplasia. J Hered 98:575-580

9. Bartels CF, Bükülmez H, Padayatti P, Rhee DK, van Ravenswaaij-Arts C, Pauli RM, Mundlos S, Chitayat D, Shih LY, Al-Gazali LI, Kant S, Cole T, Morton J, Cormier-Daire V, Faivre L, 
Lees M, Kirk J, Mortier GR, Leroy J, Zabel B, Kim CA, Crow Y, Braverman NE, van den Akker F, Warman ML (2004) Mutations in the transmembrane natriuretic peptide receptor NPR-B impair skeletal growth and cause acromesomelic dysplasia, type Maroteaux. Am J Hum Genet 75:27-34

10. The Jackson Laboratory Available from: <http://www.jax.org/index.html>

11. Jiao Y, Yan J, Jiao F, Yang H, Donahue LR, Li X, Roe BA, Stuart J, Gu W (2007) A single nucleotide mutation in Nppc is associated with a long bone abnormality in lbab mice. BMC Genet 8:16

12. Tsuji T, Kondo E, Yasoda A, Inamoto M, Kiyosu C, Nakao K, Kunieda T (2008) Hypomorphic mutation in mouse Nppc gene causes retarded bone growth due to impaired endochondral ossification. Biochem Biophys Res Commun 376:186-190

13. Yoder AR, Kruse AC, Earhart CA, Ohlendorf DH, Potter LR (2008) Reduced ability of C-type natriuretic peptide (CNP) to activate natriuretic peptide receptor B (NPR-B) causes dwarfism in lbab -/- mice. Peptides 29:1575-1581

14. Suda M, Ogawa Y, Tanaka K, Tamura N, Yasoda A, Takigawa T, Uehira M, Nishimoto H, Itoh H, Saito Y, Shiota K, Nakao K (1998) Skeletal overgrowth in transgenic mice that overexpress brain natriuretic peptide. Proc Natl Acad Sci U S A 95:2337-2342

15. Yasoda A, Ogawa Y, Suda M, Tamura N, Mori K, Sakuma Y, Chusho H, Shiota K, Tanaka K, Nakao K (1998) Natriuretic peptide regulation of endochondral ossification. Evidence for possible roles of the C-type natriuretic peptide/guanylyl cyclase-B pathway. J Biol Chem 273:11695-11700

16. Vortkamp A, Lee K, Lanske B, Segre GV, Kronenberg HM, Tabin CJ (1996) Regulation of rate of cartilage differentiation by Indian hedgehog and PTH-related protein. Science 273:613-622

17. Zhou G, Garofalo S, Mukhopadhyay K, Lefebvre V, Smith CN, Eberspaecher H, de Crombrugghe B (1995) A 182 bp fragment of the mouse pro alpha 1(II) collagen gene is sufficient to direct chondrocyte expression in transgenic mice. J Cell Sci 108 ( $\mathrm{Pt}$ 12):3677-3684 
18. Inoue A, Hiruma Y, Hirose S, Yamaguchi A, Furuya M, Tanaka S, Hagiwara H (1996) Stimulation by C-type natriuretic peptide of the differentiation of clonal osteoblastic MC3T3-E1 cells. Biochem Biophys Res Commun 221:703-707

19. Hagiwara H, Inoue A, Yamaguchi A, Yokose S, Furuya M, Tanaka S, Hirose S (1996) cGMP produced in response to ANP and CNP regulates proliferation and differentiation of osteoblastic cells. Am J Physiol 270:C1311-1318

20. Suda M, Tanaka K, Fukushima M, Natsui K, Yasoda A, Komatsu Y, Ogawa Y, Itoh H, Nakao K (1996) C-type natriuretic peptide as an autocrine/paracrine regulator of osteoblast. Evidence for possible presence of bone natriuretic peptide system. Biochem Biophys Res Commun 223:1-6

21. Yanaka N, Akatsuka H, Kawai E, Omori K (1998) 1,25-Dihydroxyvitamin D3 upregulates natriuretic peptide receptor-C expression in mouse osteoblasts. Am J Physiol 275:E965-973

22. Inoue A, Hayakawa T, Otsuka E, Kamiya A, Suzuki Y, Hirose S, Hagiwara H (1999) Correlation between induction of expression of biglycan and mineralization by C-type natriuretic peptide in osteoblastic cells. J Biochem 125:103-108

23. Suda M, Komatsu Y, Tanaka K, Yasoda A, Sakuma Y, Tamura N, Ogawa Y, Nakao K (1999) C-Type natriuretic peptide/guanylate cyclase B system in rat osteogenic ROB-C26 cells and its down-regulation by dexamethazone. Calcif Tissue Int 65:472-478

24. Inoue A, Kamiya A, Ishiji A, Hiruma Y, Hirose S, Hagiwara H (2000) Vasoactive peptide-regulated gene expression during osteoblastic differentiation. J Cardiovasc Pharmacol 36:S286-289

25. Inoue A, Kobayashi Y, Ishizuka M, Hirose S, Hagiwara H (2002) Identification of a novel osteoblastic gene, inducible by C-type natriuretic peptide, whose transcript might function in mineralization as a noncoding RNA. Calcif Tissue Int 70:111-116

26. Yeh LC, Zavala MC, Lee JC (2006) C-type natriuretic peptide enhances osteogenic protein-1-induced osteoblastic cell differentiation via Smad5 phosphorylation. J Cell Biochem 97:494-500

27. Kaneki H, Kurokawa M, Ide H (2008) The receptor attributable to C-type natriuretic 
peptide-induced differentiation of osteoblasts is switched from type B- to type C-natriuretic peptide receptor with aging. J Cell Biochem 103:753-764

28. Holliday LS, Dean AD, Greenwald JE, Glucks SL (1995) C-type natriuretic peptide increases bone resorption in 1,25-dihydroxyvitamin D3-stimulated mouse bone marrow cultures. J Biol Chem 270:18983-18989

29. Hachiya R, Ohashi Y, Kamei Y, Suganami T, Mochizuki H, Mitsui N, Saitoh M, Sakuragi M, Nishimura G, Ohashi H, Hasegawa T, Ogawa Y (2007) Intact kinase homology domain of natriuretic peptide receptor-B is essential for skeletal development. J Clin Endocrinol Metab 92:4009-4014

30. Superti-Furga A, Unger S (2007) Nosology and classification of genetic skeletal disorders: 2006 revision. Am J Med Genet A 143:1-18

31. Olney RC, Bükülmez H, Bartels CF, Prickett TC, Espiner EA, Potter LR, Warman ML (2006) Heterozygous mutations in natriuretic peptide receptor-B (NPR2) are associated with short stature. J Clin Endocrinol Metab 91:1229-1232 


\section{Figure Legends}

\section{Fig. 1}

Growth and skeletal phenotype of $l b a b /+$ and $l b a b / l b a b$ mice.

(a), (b) Naso-anal lengths (a) and body weights (b) of female wild-type (Wt, $\diamond), l b a b /+(\square)$, and lbab/lbab $(\triangle)$ mice $(\mathrm{n}=2-8)$. (c) Whole skeletons of wild-type, $l b a b /+$, and $l b a b / l b a b$ mice at 2 weeks of age. Wt, wild-type. Scale bar, $1 \mathrm{~cm}$. (d) Histological analysis of the tibial growth plates of 3-day-old mice. Arrows indicate hypertrophic chondrocyte layers. Alcian blue and hematoxylin-eosin staining. Scale bar, $100 \mu \mathrm{m}$

\section{Fig. 2}

The Effect of CNP overexpression on impaired endochondral bone growth of $l b a b / l b a b$ mice.

Whole skeletons ( $a, c)$ and bone lengths measured on soft X-ray films (b, d) of female wild-type (Wt), $l b a b / l b a b$, and $l b a b / l b a b \bullet C N P-T g$ mice at the age of 2 weeks (a, b) and 10 weeks (c, d). (a), (c) Scale bar, $1 \mathrm{~cm}$, each. (b), (d) White bars, wild-type mice; black bars, lbab/lbab mice; gray bars, lbab/lbab•CNP-Tg mice. CW, width of cranium; CL, longitudinal length of cranium; HL, humeral length; RL, radial length; UL, ulnar length; FL, femoral length; TL, tibial length; VL, vertebral length. $\mathrm{n}=2-7(\mathrm{~b})$ and $3-5(\mathrm{~d})$

\section{Fig. 3}

Histological analysis of tibial growth plates from 2-week-old wild-type (Wt), lbab/lbab, and $l b a b / l b a b \bullet C N P-T g$ mice.

(a) Alcian blue and hematoxylin-eosin staining. Yellow bars (depicted as "P") indicate proliferative chondrocyte layers, and red bars (depicted as " $\mathrm{H}$ ") indicate hypertrophic chondrocyte layers. (b) Immunohistochemical staining for type $\mathrm{X}$ collagen. Scale bar in (a), (b), $100 \mu \mathrm{m}$, each. (c), (d) Heights of the proliferative (c) and hypertrophic (d) chondrocyte layers. $\mathrm{n}=3$, each. *, $\mathrm{P}<0.05$; **, $\mathrm{P}$ $<0.01$. (e) The proportion of PCNA-positive chondrocytes in proliferative chondrocyte layers. $\mathrm{n}=$ 
3-4. **, P < 0.01. (f), (g) Immunohistochemical staining of Ihh (f) and MMP-13 (g). Scale bar in (f), (g), $50 \mu \mathrm{m}$, each.

\section{Fig. 4}

Histological analysis of tibial growth plate from female 10-week-old wild-type (Wt), lbab/lbab, and $l b a b / l b a b \bullet C N P-T g$ mice.

(a) Alcian blue and hematoxylin-eosin staining. Arrows indicate the width of growth plates. Scale bar, $50 \mu \mathrm{m}$. (b) Total heights of the growth plates. $\mathrm{n}=2-5$, each

\section{Fig. 5}

Micro CT analysis of humeri from wild-type (Wt), lbab/lbab, and $l b a b / l b a b \bullet C N P-T g$ mice at the age of 10 weeks. Scale bar, $1 \mathrm{~mm}$

\section{Fig. 6}

The effect of CNP on cultured tibiae from fetal $l b a b /+$ or $l b a b / l b a b$ mice.

(a) A representative picture of a tibial explant from a fetal mouse. Total longitudinal length (Total) and the sum lengths of cartilaginous primordia (CP) are indicated. (b), (c) Graphs of Total (b) and CP (c) lengths of cultured tibiae from $l b a b /+$ and $l b a b / l b a b$ mice treated with vehicle (veh.) or $10^{-7} \mathrm{M} \mathrm{CNP}$ (CNP) for 4 days. Circles indicate $l b a b /+$ tibiae, and squares indicate $l b a b / l b a b$ tibiae. At the end of culture, closed symbols indicate tibiae treated with vehicle, and open symbols indicate those treated with CNP. $\mathrm{n}=8-12$, each

\section{Fig. 7}

Histological analyses of the growth plates of tibial explants from fetal $l b a b /+$ or $l b a b / l b a b$ mice treated with vehicle (veh.) or $10^{-7} \mathrm{M} \mathrm{CNP}(\mathrm{CNP})$ for 4 days.

(a), (b) Alcian blue and hematoxylin-eosin staining (a) and immunohistochemical staining for type X collagen (b). Yellow bars in (a) indicate lengths of cartilaginous primordia and red bars in (b) indicate 
heights of hypertrophic chondrocyte layers. Scale bar, $200 \mu \mathrm{m}$ in each panel. (c), (d) Height of hypertrophic chondrocyte layer (c) and proportion of BrdU-positive cells (d) of the growth plate of tibial explant from fetal $l b a b /+$ or $l b a b / l b a b$ mice treated with $10^{-7} \mathrm{M} \mathrm{CNP}$ or vehicle at the end of the 4-day culture period. $\mathrm{n}=3$, each. **, $\mathrm{P}<0.01$ in (c), and $\mathrm{n}=2-3$ each in (d).

\section{Fig. 8}

Immunohistochemical staining of type $\mathrm{X}$ collagen (upper panels) and Ihh (lower panels) of the growth plates of metatarsal explants from fetal $l b a b /+$ or $l b a b / l b a b$ mice treated with vehicle (veh.) or $10^{-7}$ M CNP for 4 days. Scale bar, $50 \mu \mathrm{m}$. 
a

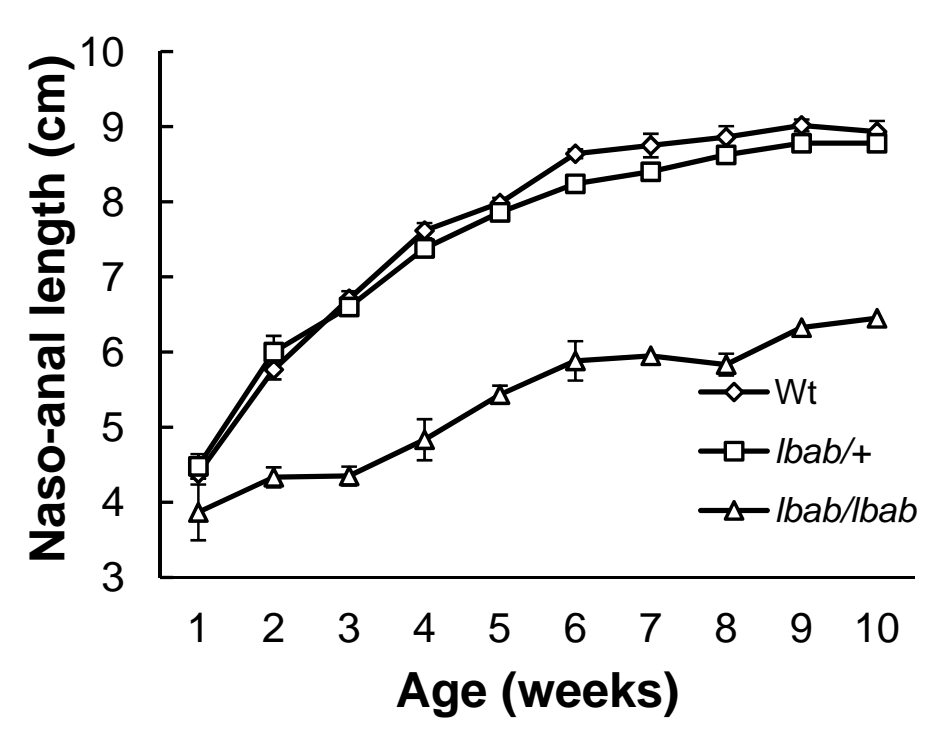

C

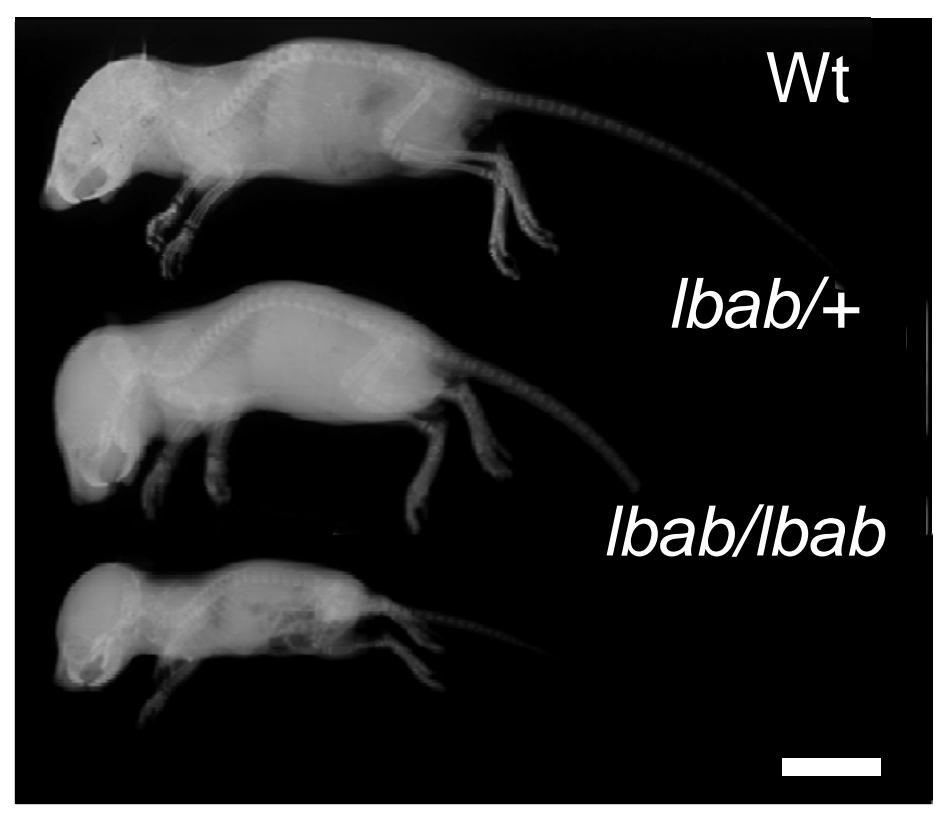

b

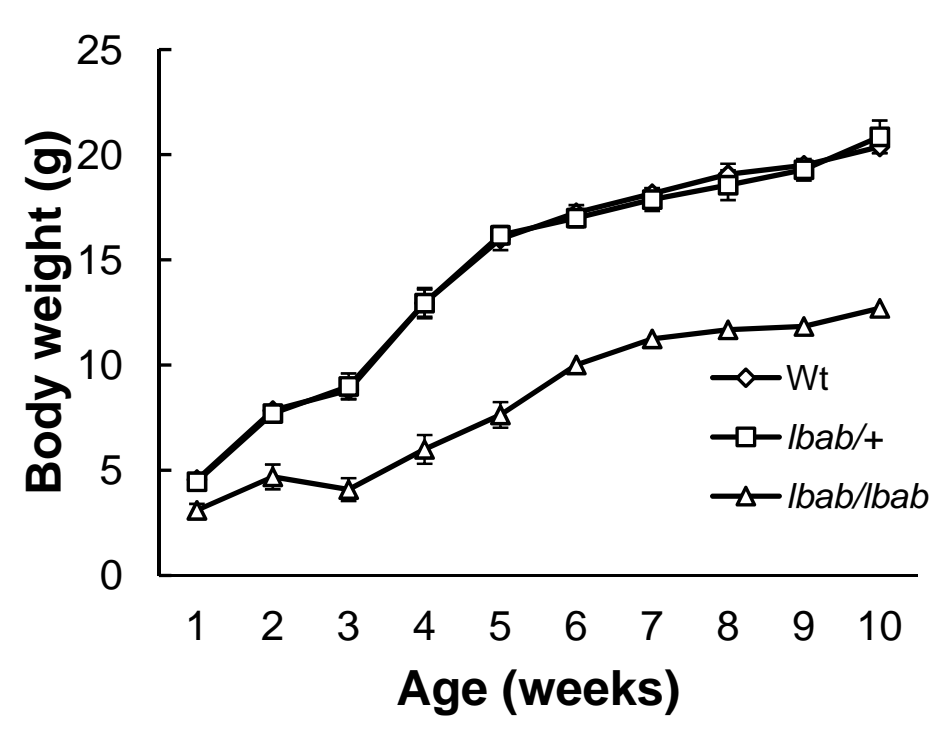

d
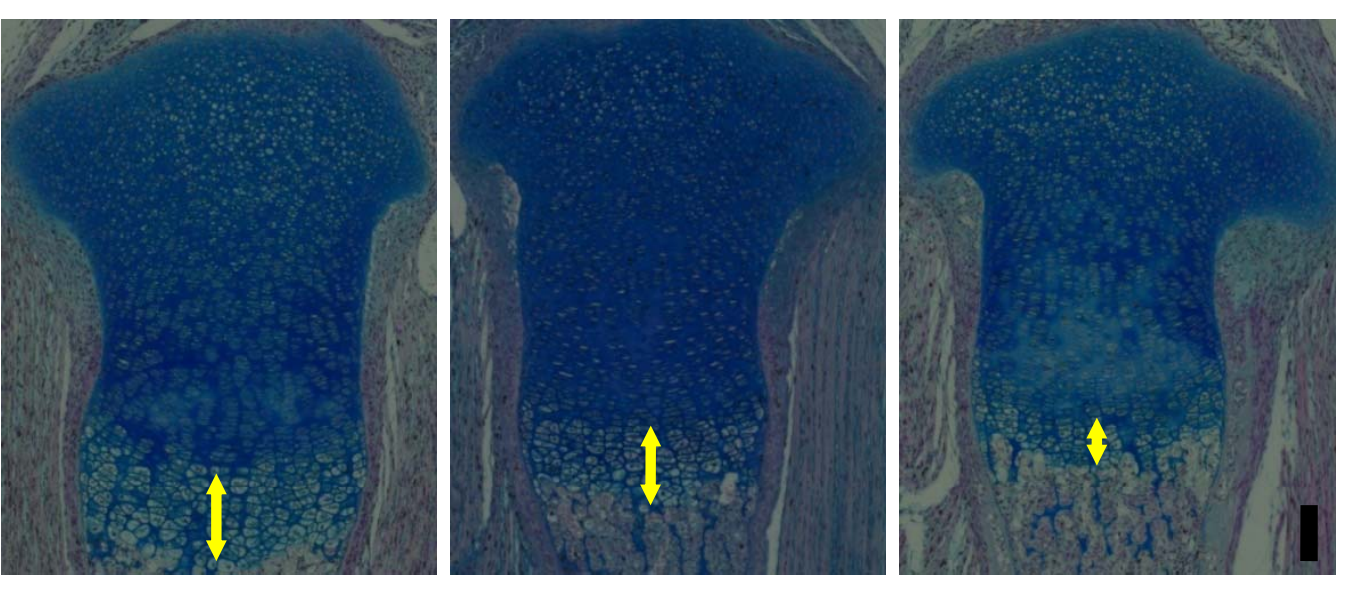

Wt lbab/lbab

Fig. 1 

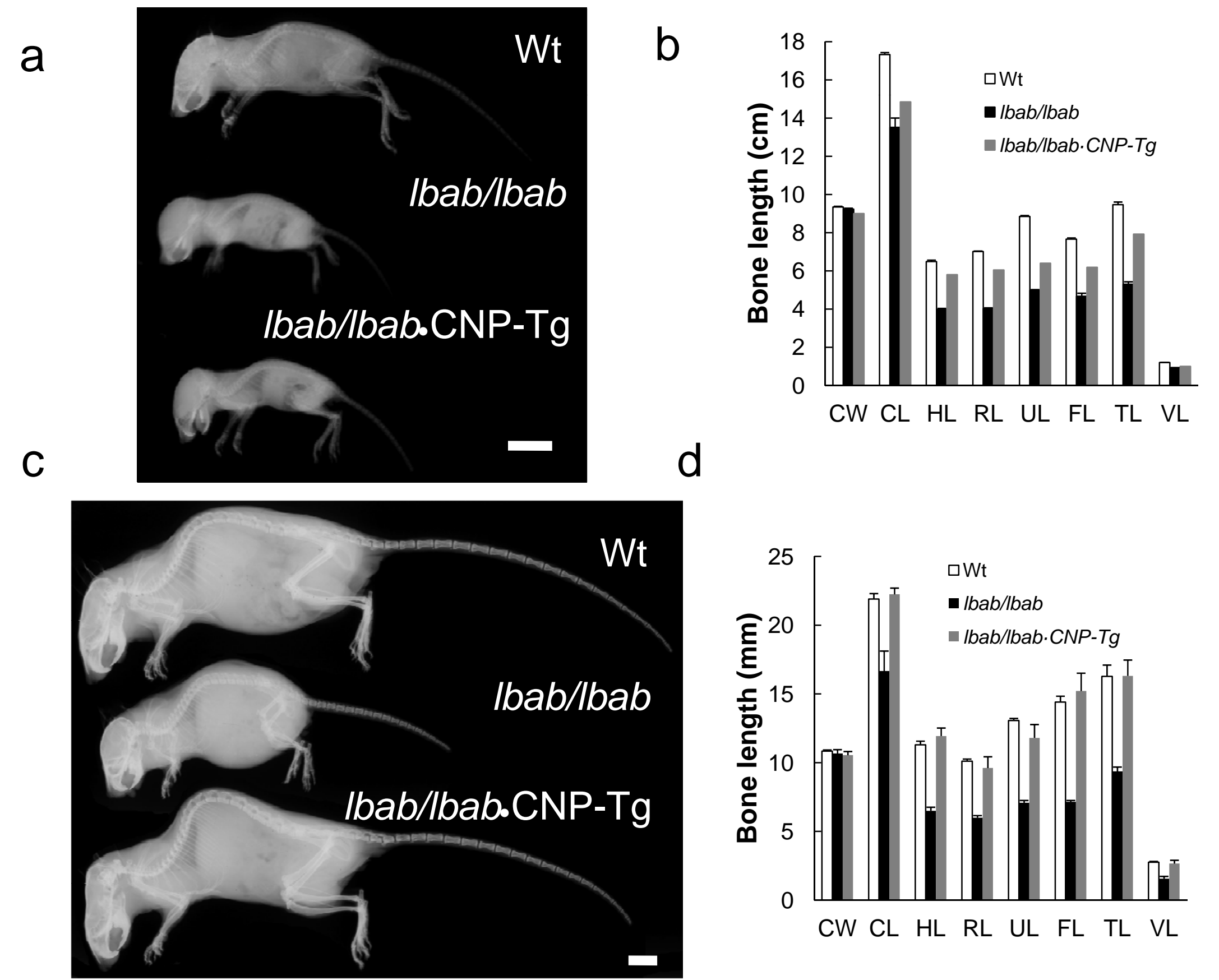

Fig. 2 
a
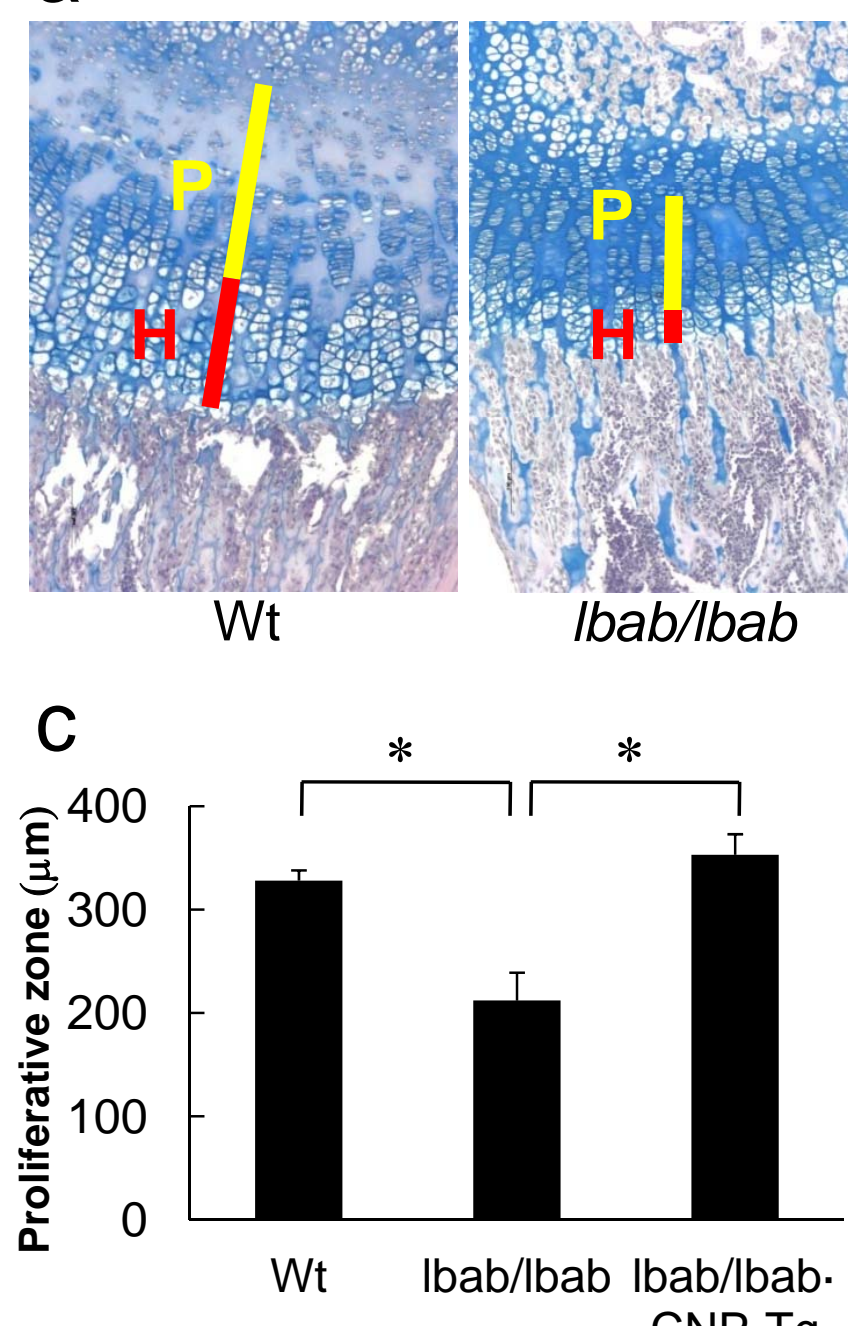

f

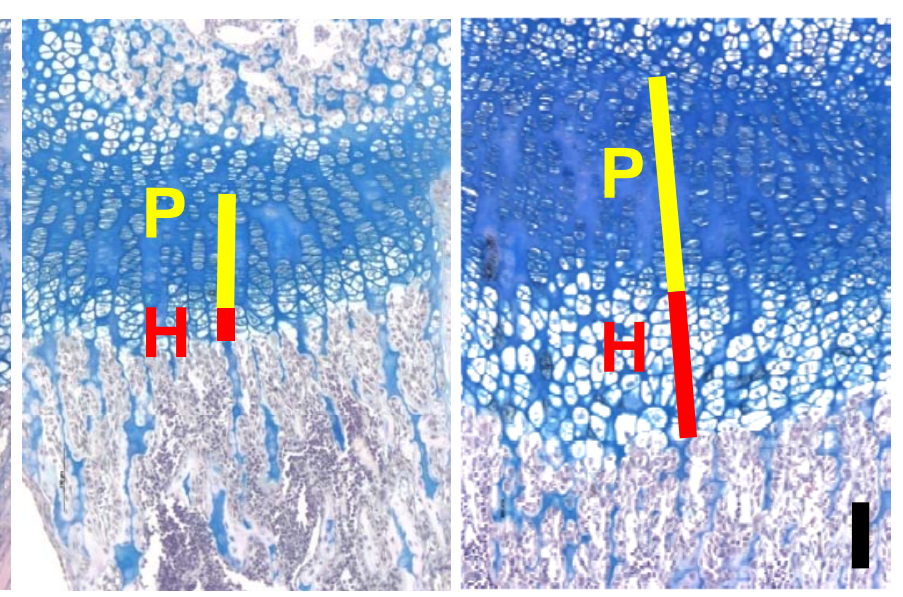

lbab/lbab•

b

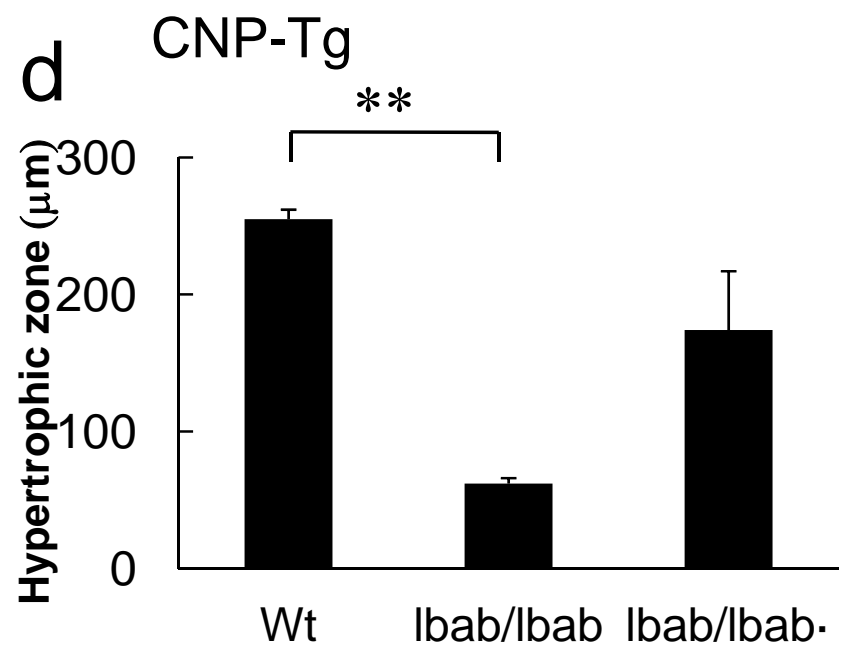

g

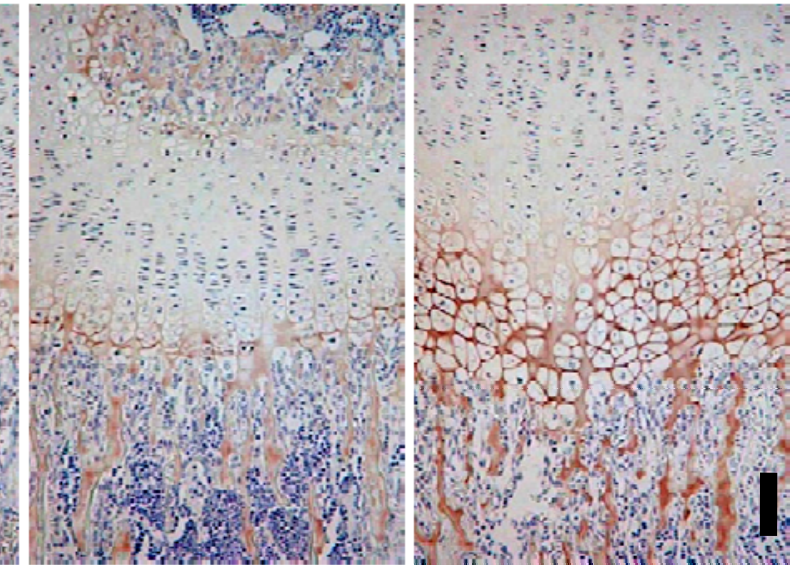

lbab/lbab

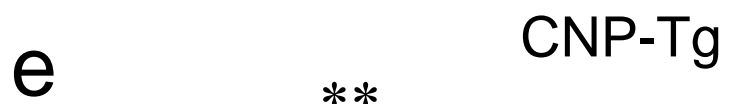

e

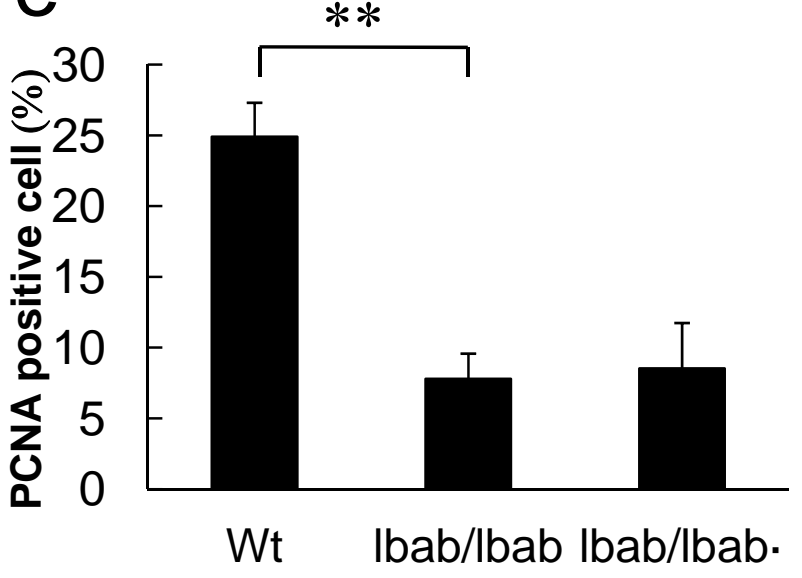

CNP-Tg
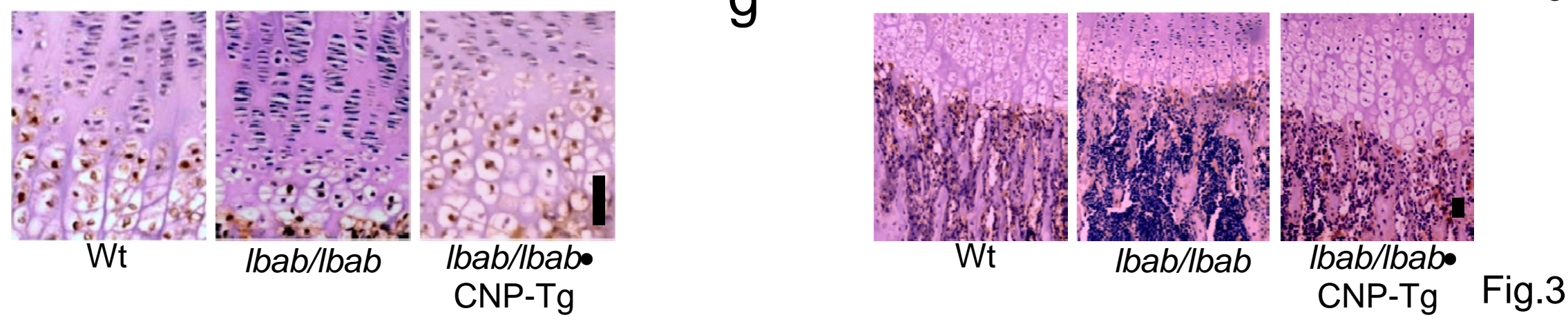
a

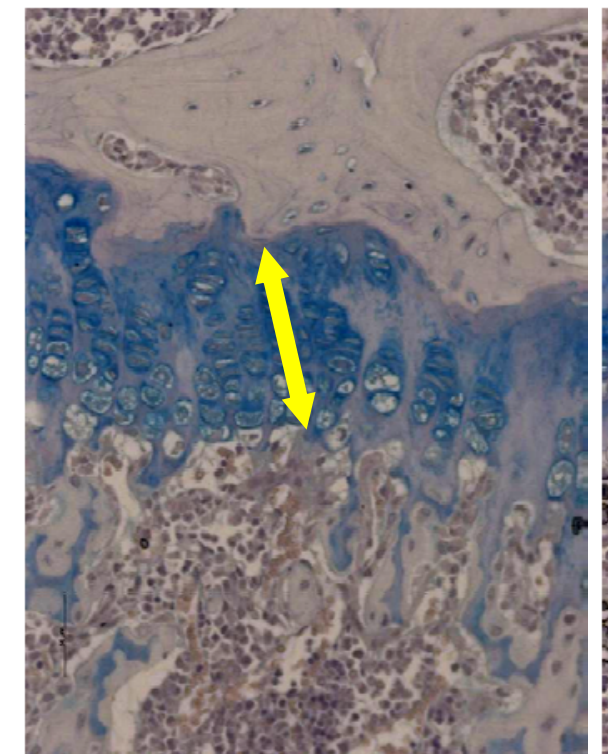

Wt

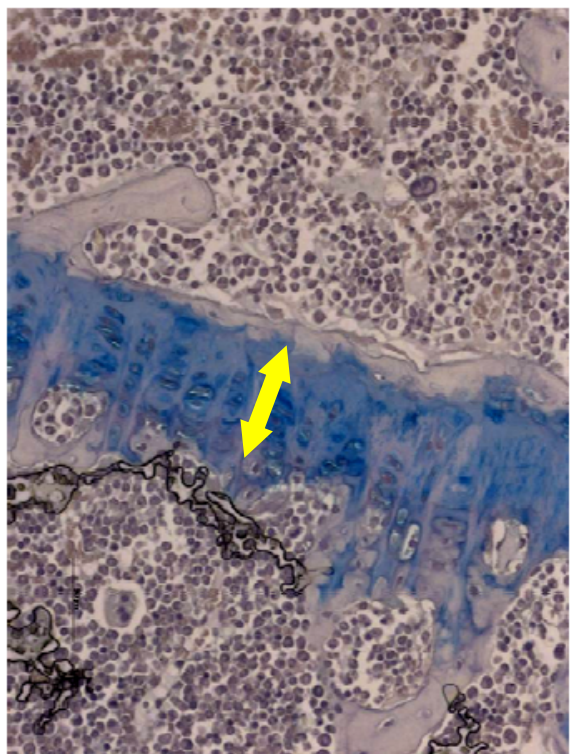

lbab/lbab

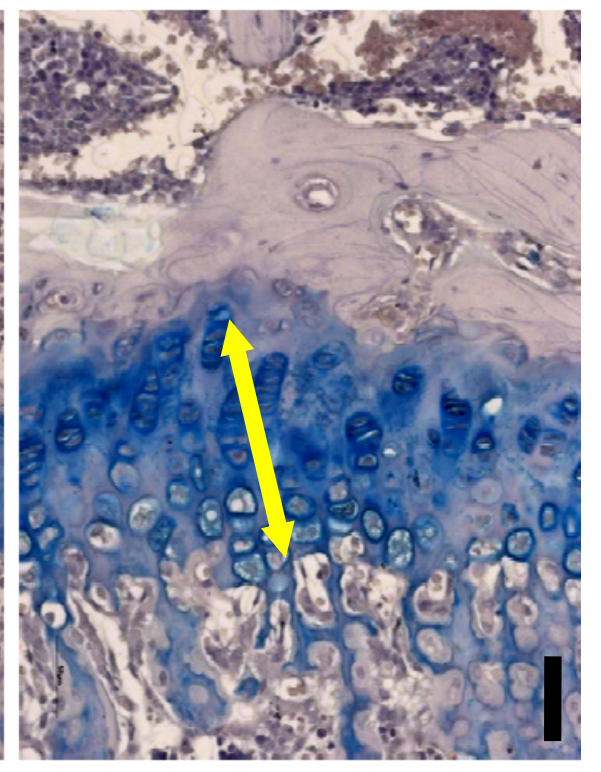

Ibab/lbab.

CNP-Tg

b

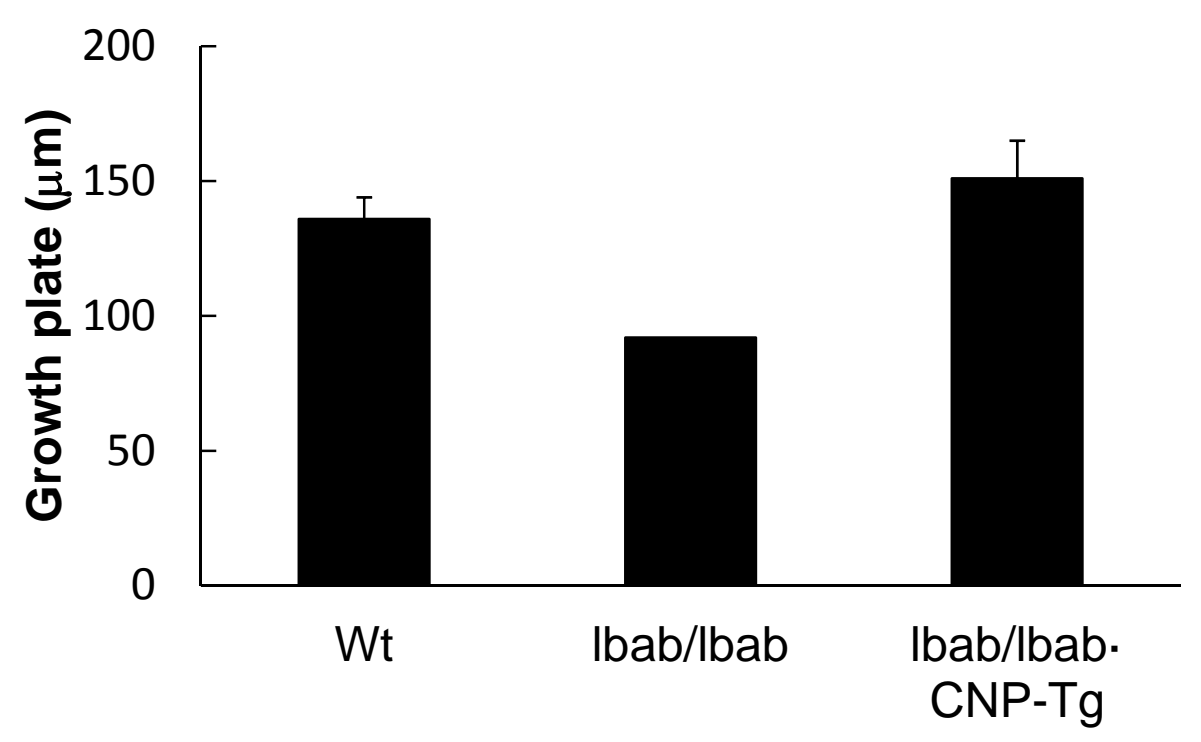

Fig. 4 


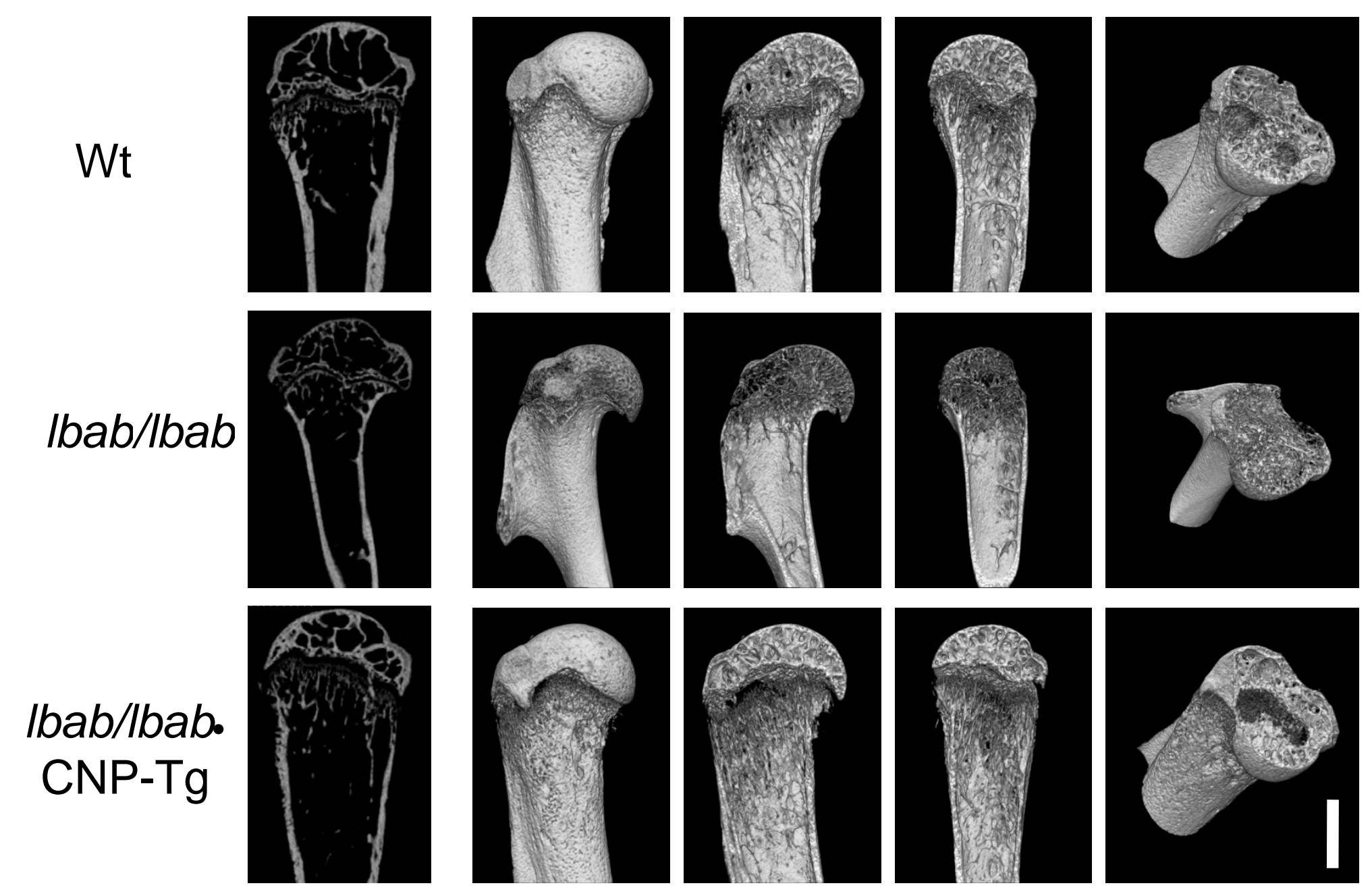

Fig. 5 
a

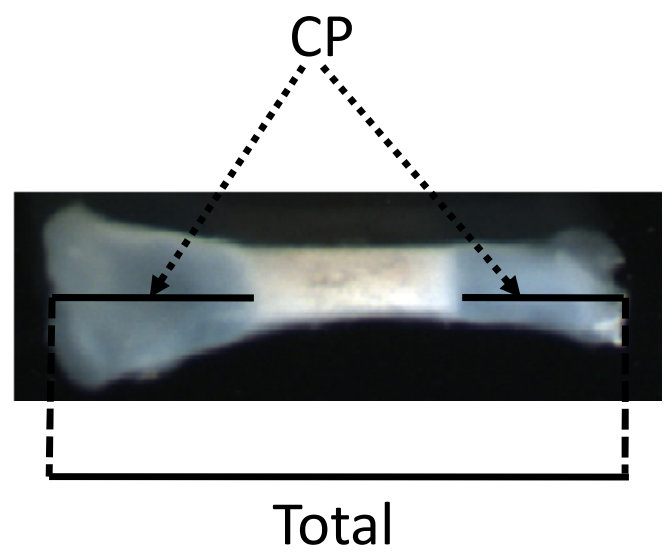

b

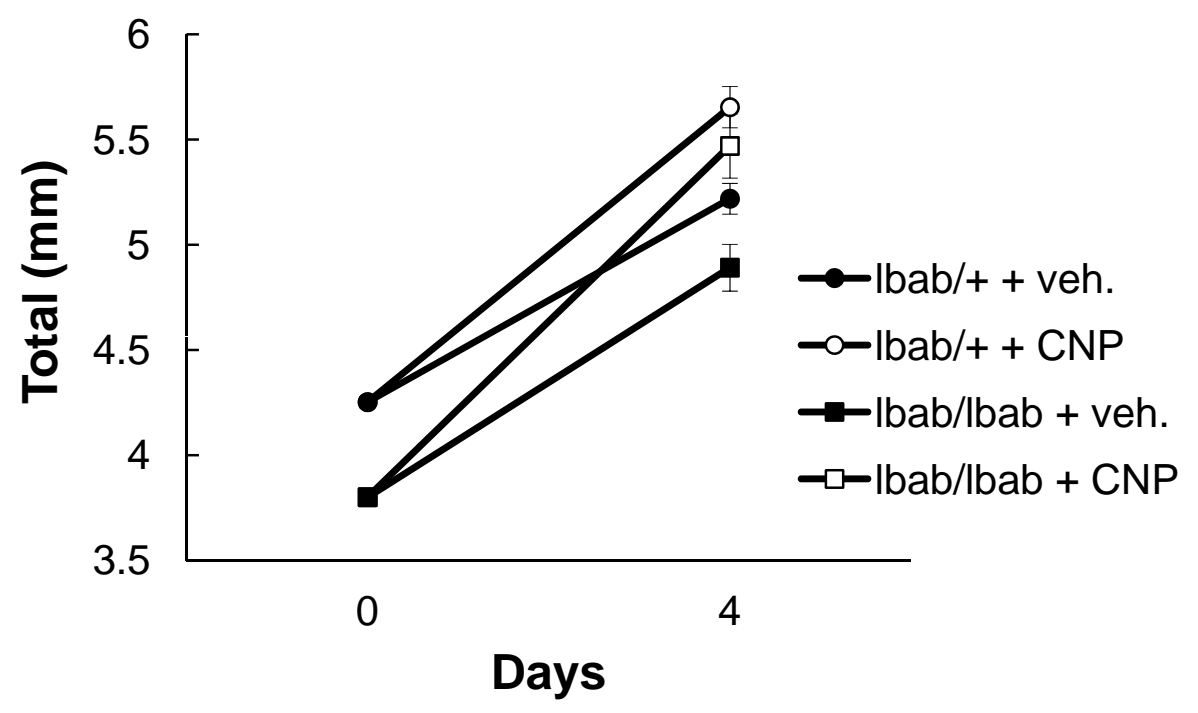

C

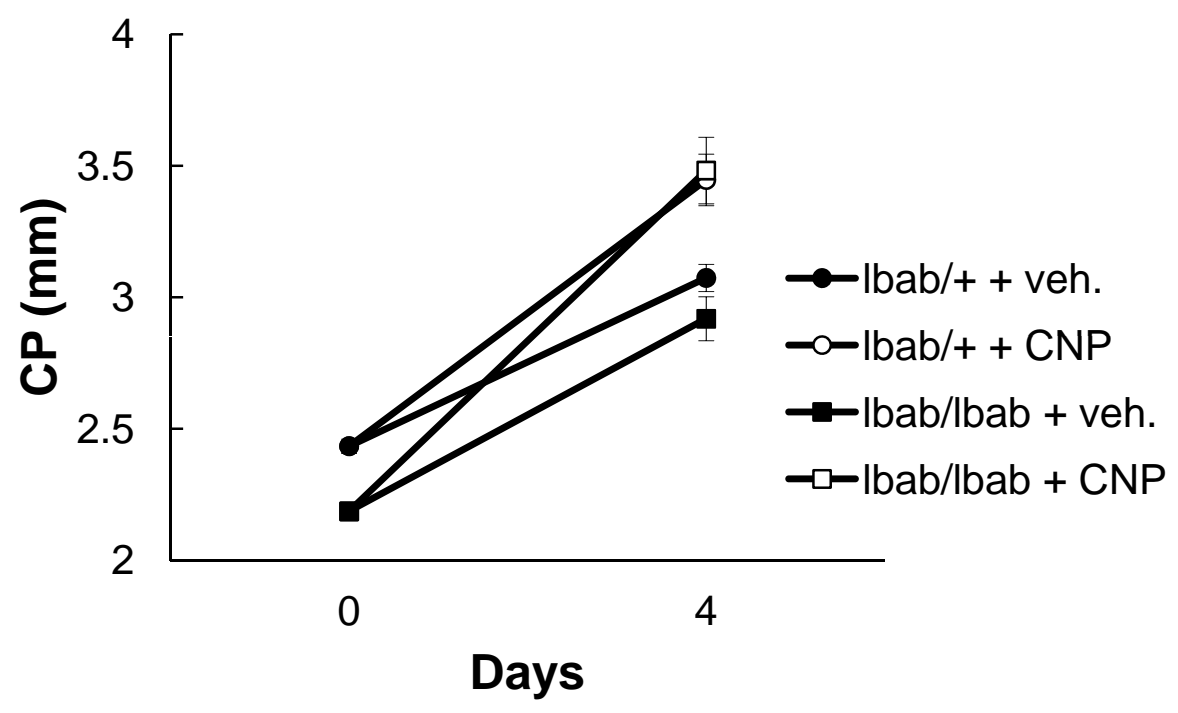

Fig. 6 


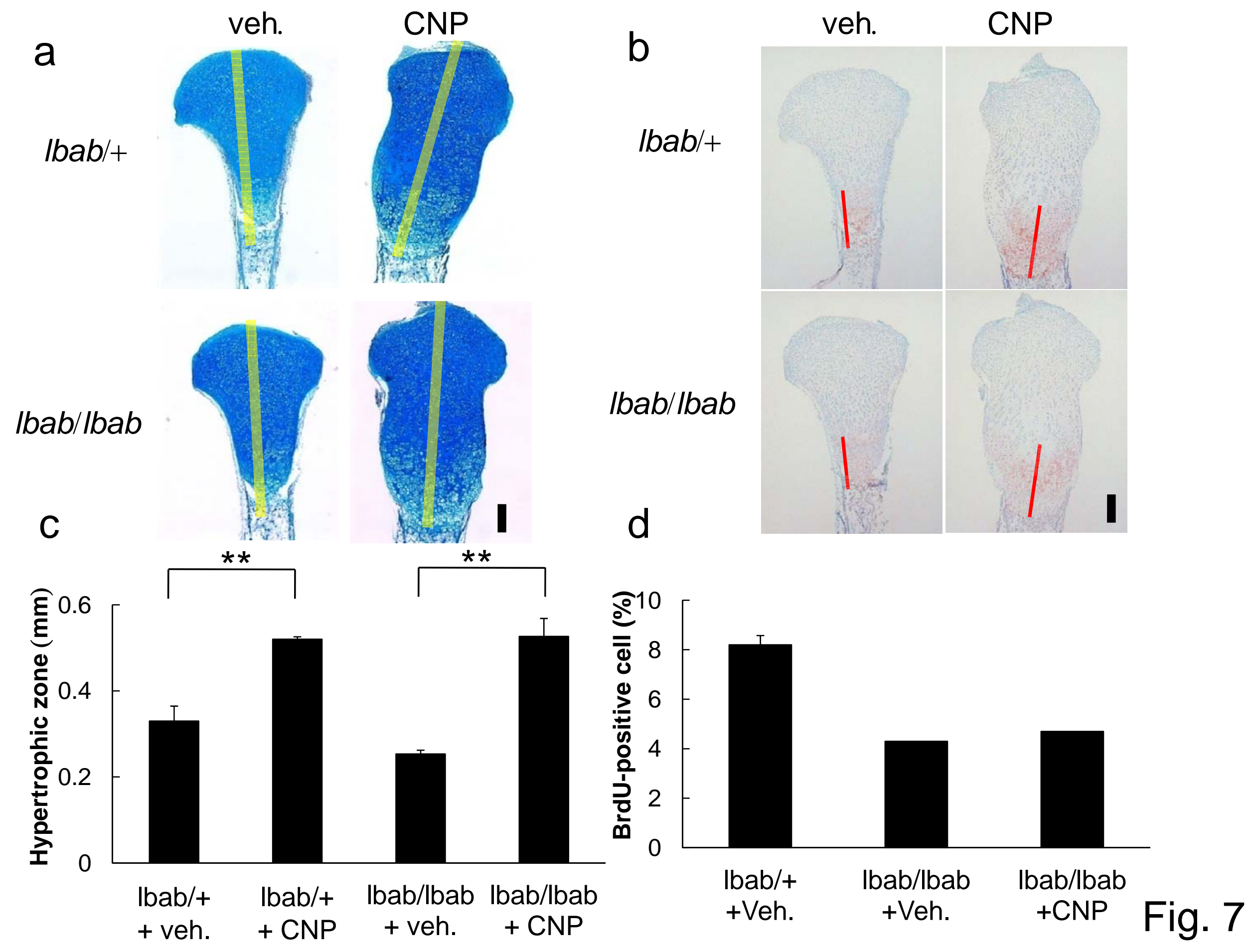




$$
\text { lbab/+ + veh. } \quad / b a b / / b a b+v e h . \quad l b a b / / b a b+C N P
$$

$\operatorname{col} X$
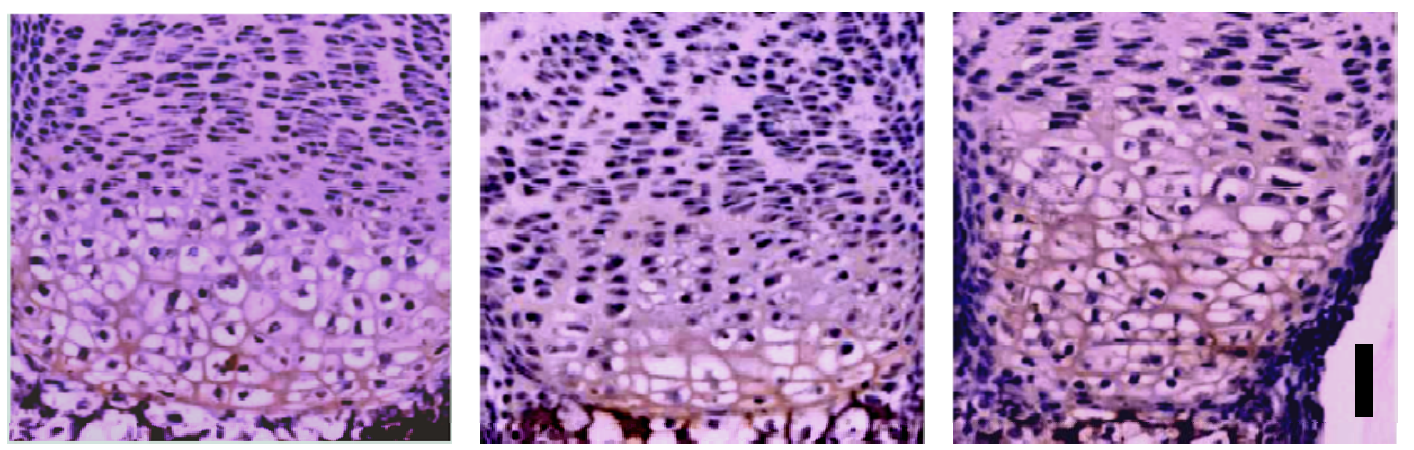

Ihh
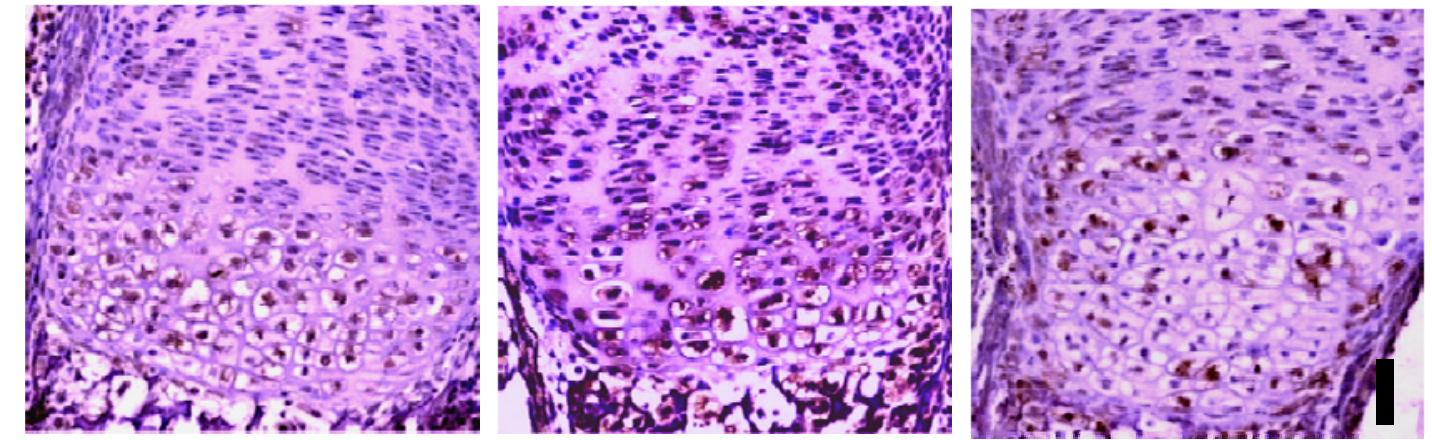

Fig.8 
Supplemental Fig. 1

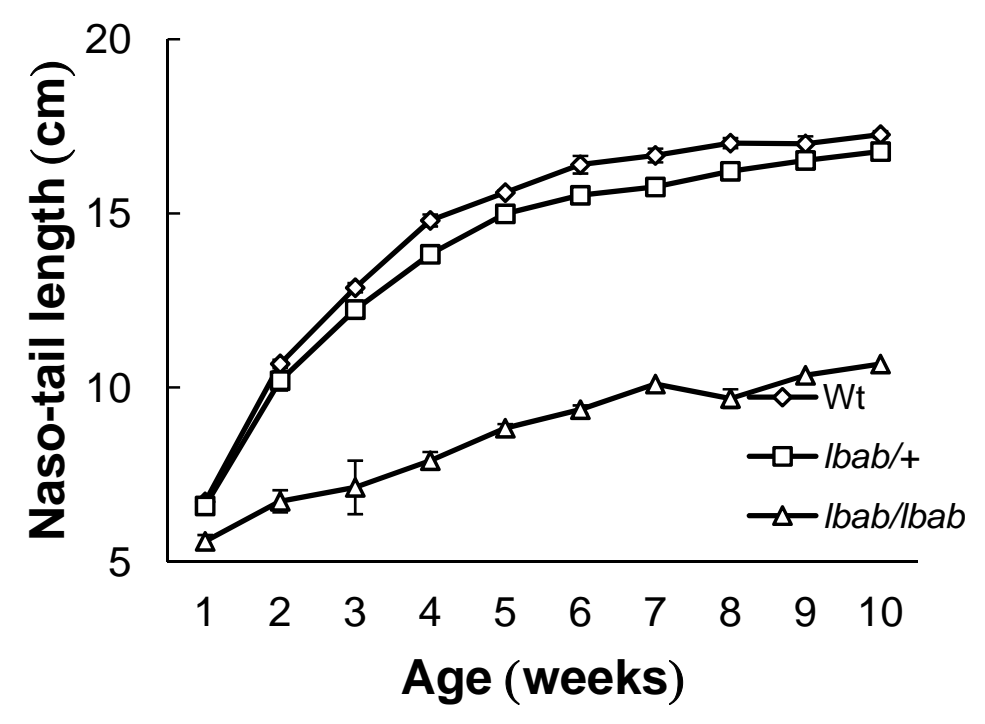




\section{Supplemental Fig. 2}

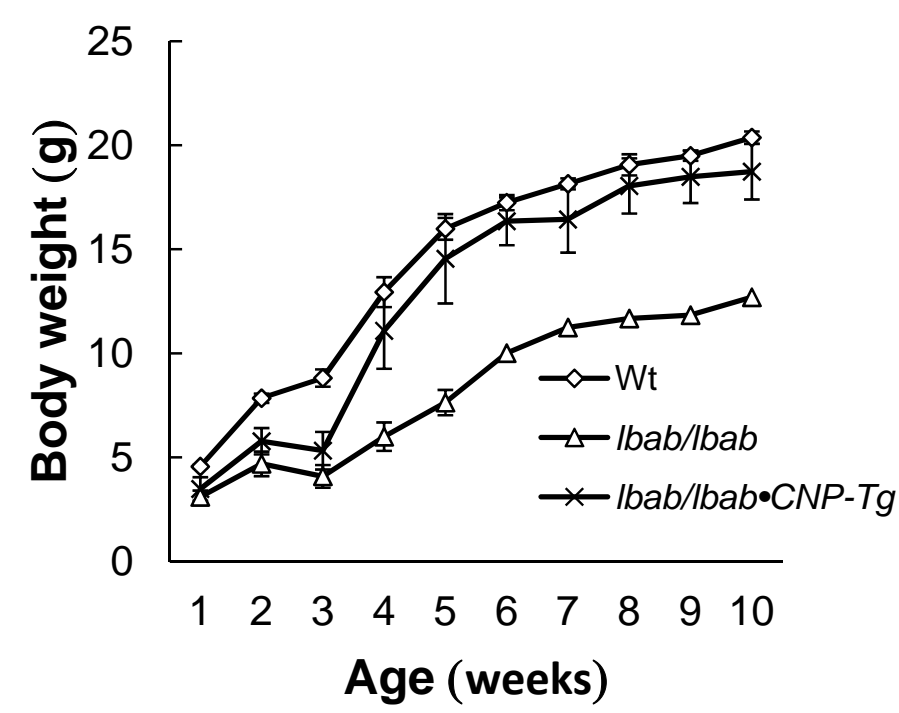


Supplemental Fig. 3

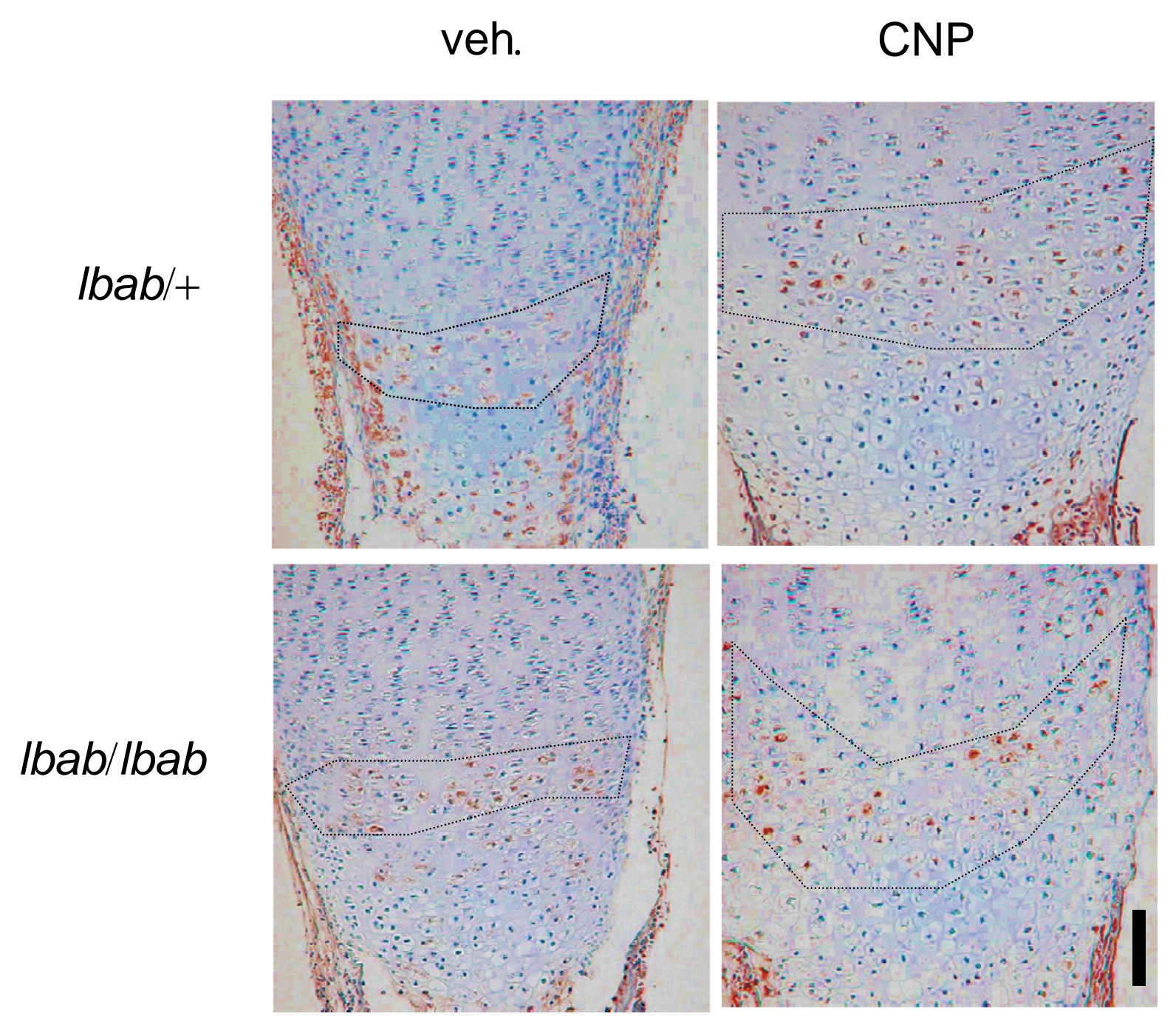

